\title{
ÍNDICE DE PROCESSIBILIDADE PARA TOMADA DE DECISÃO COMO APOIO AO PLANEJAMENTO ESTRATÉGICO
}

\section{PROCESSIBILITY INDEX FOR DECISION-MAKING AS SUPPORT FOR STRATEGIC PLANNING \\ ÍNDICE DE PROCESIBILIDAD PARA LA TOMA DE DECISIÓN COMO APOYO AL PLANEAMIENTO ESTRATÉGICO}

\section{Rafael Alvise Alberti}

Mestrando em Sistemas e Processos Industriais / Universidade de Santa Cruz do Sul; Engenheiro de Produção Endereço: Av. Independência, 2293, Bairro Universitário, CEP: 96815-900. Santa Cruz do Sul, RS, Brasil Telefone: 51-3717-7632. E-mail: alberti_rafael@yahoo.com.br

\section{Elpídio Oscar Benitez Nara}

Professor / Universidade de Santa Cruz do Sul; Doutor em Engenharia de Produção Endereço: Av. Independência, 2293, Bairro Universitário, CEP: 96815-900. Santa Cruz do Sul, RS, Brasil Telefone: 51-3717-7632.E-mail: elpidio@unisc.br

\section{João Carlos Furtado}

Professor / Universidade de Santa Cruz do Sul; Doutor em Computação Aplicada Endereço: Av. Independência, 2293, Bairro Universitário, CEP: 96815-900. Santa Cruz do Sul, RS, Brasil Telefone: 51-3717-7632 E-mail: jcarlosf@unisc.br

\section{Liane Mahlmann Kipper}

Professora / Universidade de Santa Cruz do Sul; Doutora em Engenharia de Produção Endereço: Av. Independência, 2293, Bairro Universitário, CEP: 96815-900. Santa Cruz do Sul, RS, Brasil Telefone: 51-3717-7632. E-mail: liane@unisc.br

\section{Julio Cezar Mairesse Siluk}

Professor / Universidade Federal de Santa Maria; Doutor em Engenharia de Produção Endereço: Av. Roraima, 1000, Bairro Camobi, CEP: 97105-900. Santa Maria, RS, Brasil Telefone: 55-3220-8442. E-mail: jsiluk@gmail.com

Artigo recebido em 24/01/2014. Revisado por pares em 31/03/2014. Reformulado em 03/04/2014. Recomendado para publicação em 13/07/2014 por Ademar Dutra (Editor Científico). Publicado em 29/08/2014. Avaliado pelo Sistema double blind review.
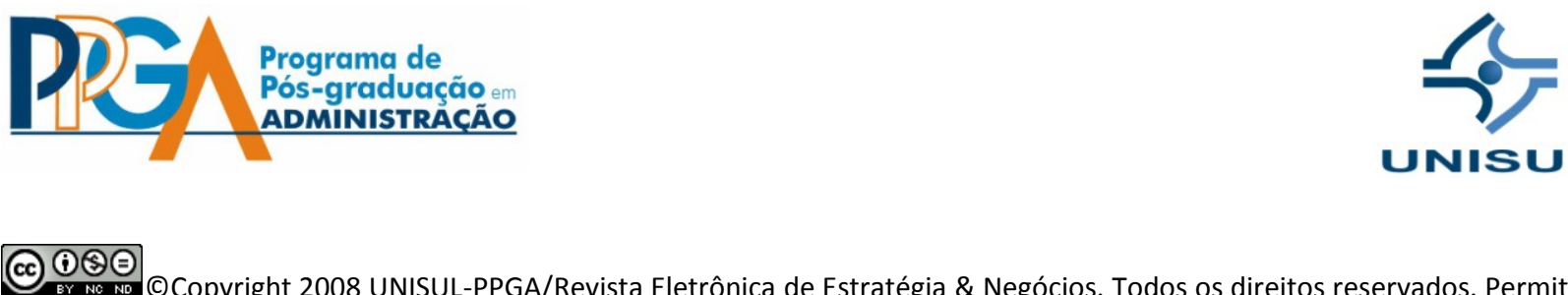

citação parcial, desde que identificada a fonte. Proibida a reprodução total. 
ÍNDICE DE PROCESSIBILIDADE PARA TOMADA DE DECISÃO COMO APOIO AO PLANEJAMENTO ESTRATÉGICO Rafael Alvise Alberti - Elpidio Oscar Benitez Nara - João Carlos Furtado - Liane Mahlmann Kipper - Julio Cezar Mairesse Siluk

\section{RESUMO}

Constantes mudanças da economia instigam pensamentos empresariais sob o olhar dos processos organizacionais. Através de pesquisa exploratório-qualitativa foram reconhecidas as características das organizações horizontais, de processos e suas abordagens, a fim de obter uma definição de processibilidade em gestão. Posteriormente foi avaliado o Índice de Processibilidade (GONÇALVES, 2000b) através de análise lógico-dedutiva, verificando a não abrangência às principais características organizacionais. Foram acrescidos novos fatores, complementando-o e propondo um novo índice. A pesquisa logra perspectivas futuras, pois este índice apenas se faz relevante frente a uma base de dados que categorize o valor encontrado, desta forma, norteando melhores decisões gerenciais.

Palavras-chave: Processibilidade; Planejamento Estratégico; Gestão por Processos; Mudanças Organizacionais.

\section{ABSTRACT}

Constant economy changes instigate business thoughts under the gaze of organizational processes. Horizontal organizations characteristics were recognized through an exploratoryqualitative research, and also the process definition and contextualization of the approaches by processes in order to obtain a definition of processibility in management. Posteriorly the Processibility Index proposed by Gonçalves (2000b) was evaluated through logical-deductive analysis, verifying the non-coverage the main organizational characteristics. New factors were added, complementing the existing ones and proposing a new index. The research achieves futures prospects, because this measurable index is only relevant before a database that makes possible to categorize the value found, and then, through the information generated, guide the best managerial decision tied to the strategic planning

Keywords: Processibility; Strategic Planning; Management Processes; Organizational Changes.

\section{RESUMEN}

Constantes cambios de la economía instigan pensamientos empresariales bajo la mirada de los procesos organizacionales. A través de investigación exploratoria y cualitativa fueron reconocidas las características de las organizaciones horizontales, de procesos y sus abordajes, a fin de obtener una definición de procesibilidad en gestión. Posteriormente fue evaluado el Índice de Procesibilidad (GONÇALVES, 2000b) a través de análisis lógico-deductivo, verificando la falta de cobertura de las principales características organizacionales. Fueron añadidos nuevos factores, complementándolo y proponiendo un nuevo índice. La investigación alcanza perspectivas futuras, pues este índice sólo es relevante frente a una base de datos que categorice el valor encontrado. De esta manera, permitiendo guiar hasta las mejores decisiones gerenciales.

Palabras-clave: Procesibilidad; Planeamiento Estratégico; Gestión por Procesos; Cambios Organizacionales.

Revista Eletrônica de Estratégia \& Negócios, Florianópolis, v.7, n.2, mai./ago. 2014. 
ÍNDICE DE PROCESSIBILIDADE PARA TOMADA DE DECISÃO COMO APOIO AO PLANEJAMENTO ESTRATÉGICO Rafael Alvise Alberti - Elpidio Oscar Benitez Nara - João Carlos Furtado - Liane Mahlmann Kipper - Julio Cezar Mairesse Siluk

\section{INTRODUÇÃO}

A evolução da tecnologia cada vez mais presente nas organizações, a interconexão em grandes redes (arranjos produtivos) e a integração de mercados mundiais instigaram a evolução dos pensamentos empresariais, principalmente sob o olhar da vantagem competitiva e das mudanças organizacionais e estratégicas (VASCONCELOS e CYRINO, 2000).

Uma das principais mudanças foi a utilização de processos de gestão baseados em uma abordagem sistêmica; ou seja, uma percepção das organizações de forma mais abrangente, integrando atividades através de visão horizontal dos processos e da satisfação do cliente (STORCH et al, 2013). Diante desta abordagem por processos, Gestão por Processos (GP), fica evidente que sua implantação, desde que eficaz, auxilia as organizações a conviverem com o atual dinamismo do cenário produtivo e das exigências por parte dos clientes.

Muitas empresas não possuem certeza sobre as decisões pertinente para alcançar sua estruturação por processos. Em outras palavras, não compreendem o que significa ser orientado por processos, e também existem aqueles que não têm certeza se a atual forma da organização é apropriada para a gestão eficiente e eficaz de seus processos, por isso toda a etapa de implantação gera muitas dúvidas (STORCH et al, 2013).

Os níveis de incerteza e a ambiguidade do ambiente contribuem para que as mudanças organizacionais sejam vistas como fato de ocorrência cada vez mais frequente. Tais mudanças são evidenciadas pela simples percepção de que são inevitáveis e, a ausência de estabilidade, previsibilidade e a existência de clientes cada vez mais dinâmicos e mutáveis, evidenciam as fraquezas de grande parte dos padrões utilizados nas organizações (GONÇALVES, 2000b; VASCONCELOS e CYRINO, 2000).

Neste aspecto, a organização é o reflexo da ação organizacional e é permanentemente afetada pelos indivíduos em suas ações. Tendo, também, as características concebidas pelas organizações e seu ambiente, impactando nas estratégias e definindo o limite da capacidade de aprendizagem da organização (CHERMAN e ROCHA-PINTO, 2013).

Revista Eletrônica de Estratégia \& Negócios, Florianópolis, v.7, n.2, mai./ago. 2014. 
ÍNDICE DE PROCESSIBILIDADE PARA TOMADA DE DECISÃO COMO APOIO AO PLANEJAMENTO ESTRATÉGICO Rafael Alvise Alberti - Elpidio Oscar Benitez Nara - João Carlos Furtado - Liane Mahlmann Kipper - Julio Cezar Mairesse Siluk

194

Durante o período de transição entre modelos gerenciais, há coexistência e incoerência dentro da gestão, pois, tradicionalmente, os indivíduos (gestores ou não) se protegem engessando e defendendo a identidade organizacional já existente e, por isso, é indispensável a utilização de uma ferramenta que auxilie na decisão, esclarecendo a situação para que possam ser analisadas as vantagens da adoção de uma abordagem por processos (SCHIAR e DOMINGUES, 2002; SCHÜTZ et al, 2011; KIPPER et al, 2011; CHERMAN e ROCHAPINTO 2013).

Deste modo, a adoção da GP não deve ser desvinculada do planejamento estratégico, uma vez que este contribui para a definição da capacidade de resposta às mudanças do ambiente empresarial, e facilita na prática das decisões (MÜLLER, 2003). Logo, a utilização de indicadores permite antever um futuro possível, e embasar a tomada de decisões da maneira a obter o melhor feedback para a organização.

Diante do exposto, este estudo tem por intuito realizar uma análise sobre a processibilidade das organizações ante a adoção da GP, através da avaliação do índice de Processibilidade proposto por José Ernesto Lima Gonçalves (GONÇALVES, 2000b).

Portanto, a pesquisa visou a responder se o índice de processibilidade proposto por Gonçalves (2000b) é demasiadamente abrangente; se contempla as principais características das organizações geridas por processos; se está vinculado a uma ideia atual de processibilidade; e se apresenta uma resposta concisa, um feedback capaz de auxiliar na tomada de decisões gerenciais. A motivação para tal pesquisa foi o fato que, desde a apresentação do índice, poucas foram as produções científicas que buscaram avaliar ou discutir o mesmo, seja para legitimá-lo ou para contrapô-lo.

Revista Eletrônica de Estratégia \& Negócios, Florianópolis, v.7, n.2, mai./ago. 2014. 


\section{FUNDAMENTAÇÃO TEÓRICA}

\subsection{PROCESSIBILIDADE}

Em se tratando de um neologismo utilizado por Gonçalves (2000b) no contexto de gestão, o termo processibilidade é de explicação e significado carente. Portanto, é necessário recorrer a outras áreas a fim de criar um contexto (Quadro1) para, posteriormente, poder postular uma definição alinhada à gestão e planejamento.

Quadro 1 - Definições de Processibilidade

\begin{tabular}{|c|c|c|}
\hline Fonte & Área & Definição \\
\hline ZITEK e TIEDENS (2012) & Psicologia & $\begin{array}{l}\text { Refere-se a processos mentais executados rapidamente, } \\
\text { com precisão, e/ou eficientemente e fluência subjetiva; } \\
\text { experiência consciente de processamento; facilidade ou } \\
\text { conhecimento que existe para processar um estímulo } \\
\text { facilmente. }\end{array}$ \\
\hline $\begin{array}{l}\text { CARPENTER, WILFORD, } \\
\text { KORNELL, MULLANEY } \\
\text { (2013) }\end{array}$ & Psicologia & Se possuir, leva a avaliações precisas de aprendizagem. \\
\hline MARCINIUK (2007) & Linguística & $\begin{array}{l}\text { Condição propícia para que se façam previsões que, } \\
\text { quando submetidas a teste, podem indicar caminhos de } \\
\text { desenvolvimento. Está relacionada aos requisitos das } \\
\text { habilidades comportamentais específicas necessárias. }\end{array}$ \\
\hline BATEN (2011) & Linguística & $\begin{array}{c}\text { Determina restrições sobre transformações; competências } \\
\text { necessárias para o processamento. }\end{array}$ \\
\hline MELLO et al (2004) & $\begin{array}{l}\text { Físico- } \\
\text { químico }\end{array}$ & $\begin{array}{l}\text { Propriedades e características que devem estar otimizadas } \\
\text { para se conseguir alta produtividade e bom desempenho. }\end{array}$ \\
\hline $\begin{array}{c}\text { BITENCOURT e } \\
\text { PANDOLFELLI (2013) }\end{array}$ & Cerâmicas & $\begin{array}{c}\text { Capacidade de processamento, de transformação àquilo } \\
\text { que se deseja. Que pode ser processado, aplicando, } \\
\text { utilizando o mínimo de insumos possível; características } \\
\text { intrínsecas às vantagens e desvantagens para o } \\
\text { processamento. }\end{array}$ \\
\hline $\begin{array}{l}\text { ROGRIGUES, FUJIYAMA, } \\
\text { OLIVEIRA, CARVALHO } \\
\text { (2010) }\end{array}$ & Usinagem & Determina um perfil de utilização adequado. \\
\hline CATEN e FRANZ (2002) & Produção & $\begin{array}{l}\text { Melhoria da eficiência e da eficácia dos processos; } \\
\text { características avaliadas por um parâmetro. }\end{array}$ \\
\hline BORGES (2011) & Produção & $\begin{array}{c}\text { Condição de previsão de características para produto e } \\
\text { parâmetros para processo. }\end{array}$ \\
\hline
\end{tabular}

Revista Eletrônica de Estratégia \& Negócios, Florianópolis, v.7, n.2, mai./ago. 2014. 
ÍNDICE DE PROCESSIBILIDADE PARA TOMADA DE DECISÃO COMO APOIO AO PLANEJAMENTO ESTRATÉGICO Rafael Alvise Alberti - Elpidio Oscar Benitez Nara - João Carlos Furtado - Liane Mahlmann Kipper - Julio Cezar Mairesse Siluk

196

\begin{tabular}{|l|l|l|}
\hline BRASIL (1988) & Legislativo & Natureza jurídica apta a processar. \\
\hline
\end{tabular}

Fonte: Elaborado pelos autores.

\subsection{O ÍNDICE DE PROCESSIBILIDADE}

Os indicadores desempenham a função de quantificar como as atividades estão em propósito com as metas, permitindo às organizações um feedback sobre seus resultados, como também o acompanhamento das variáveis de interesse, possibilitando o planejamento estratégico.

Também quantificam a eficiência e eficácia dos processos e, por isso, devem ser bem definidos, mensurando além das dimensões custos e produtividade. Tais medições devem ser derivadas da estratégia da organização, utilizando uma sistemática que contribua para o planejamento e a gestão eficiente do negócio (YU et al, 2007).

Com o principal objetivo de resumir informações, os indicadores simplificam o processo de análise e acompanhamento, dirigindo os gestores rumo às decisões mais viáveis e rentáveis, sendo considerados de suma importância na melhoria dos processos e no alcance dos objetivos traçados (MELNYK et al, 2004). Deste modo, identificam e provam (ou não) se os objetivos de um PE foram alcançados (COX et al, 2003; TOOR e OGUNLANA, 2010).

De acordo com Nara e Clane (2005), os indicadores permitem que a organização obtenha informações relevantes para a eficiência do processo, mas ressalvam que deve haver cuidado ao lidar com medições estratégicas, uma vez que uma escolha inadequada pode levar a resultados incorretos (BRITO e BRITO, 2012).

Assim, uma abordagem de gestão alinhada aos objetivos estratégicos deixa evidente a relação entre indicadores e processos como fator chave para o sucesso (KAUFMANN e BECKER, 2005). Neste contexto, um indicador aliado aos conceitos da GP, capaz de mensurar a processibilidade das organizações, corroboraria tanto com os aspectos internos, os objetivos 
das organizações; e externos, como a convivência no mercado amplamente dinâmico e competitivo, ambiente mais do que propício para a Gestão por Processos.

Deste modo, Gonçalves (2000b) propôs um Índice de Processibilidade (Figura 1), objeto de estudo do presente artigo.

Figura 1 - Índice de Processibilidade

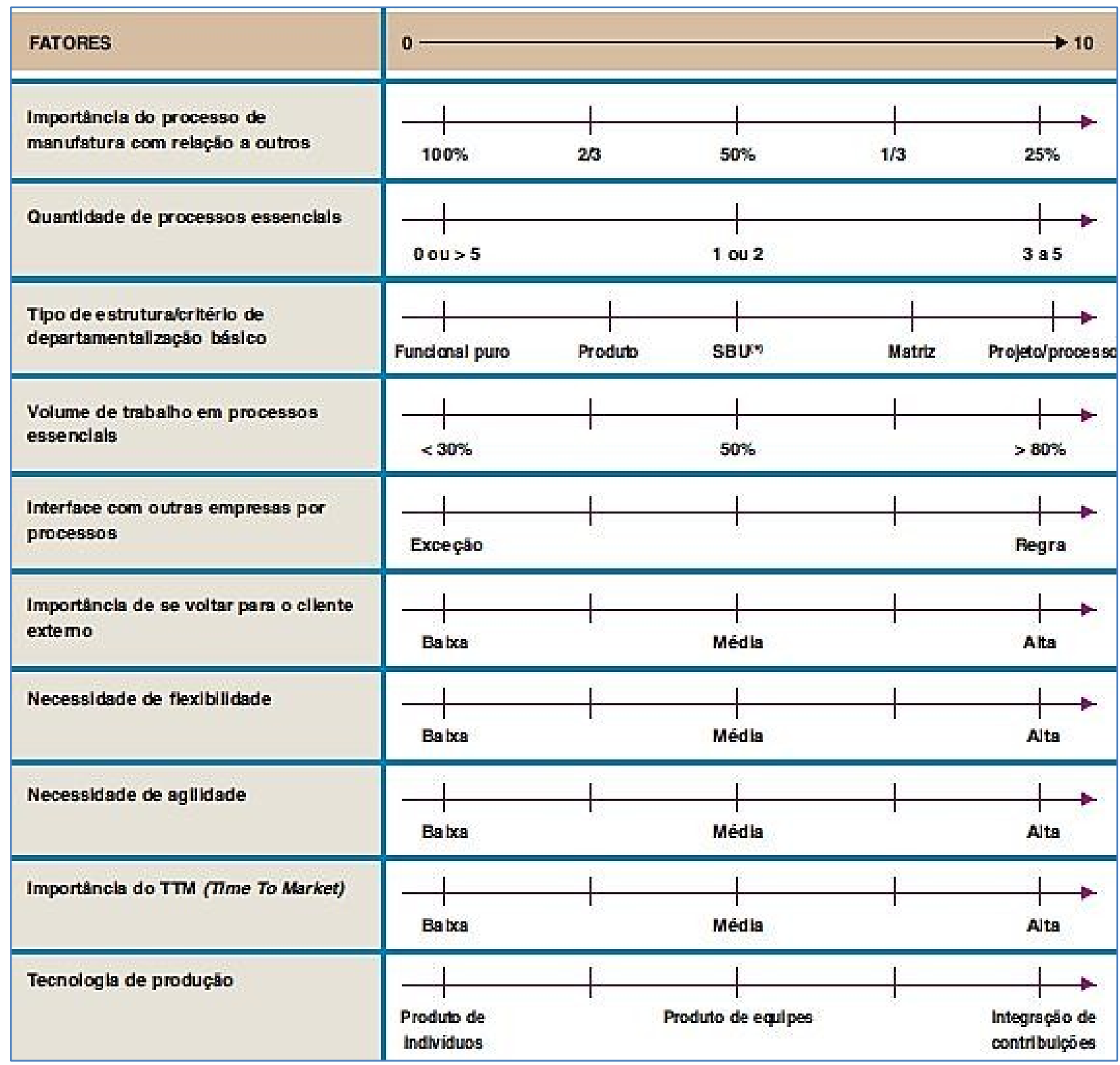

Fonte: Gonçalves (2000b).

Revista Eletrônica de Estratégia \& Negócios, Florianópolis, v.7, n.2, mai./ago. 2014. 
ÍNDICE DE PROCESSIBILIDADE PARA TOMADA DE DECISÃO COMO APOIO AO PLANEJAMENTO ESTRATÉGICO Rafael Alvise Alberti - Elpidio Oscar Benitez Nara - João Carlos Furtado - Liane Mahlmann Kipper - Julio Cezar Mairesse Siluk

198

Mesmo considerando meramente indicativo, Gonçalves (2000b) propôs um índice que aborda, de forma simplificada, os dez fatores mais importantes na decisão da adoção de uma organização por processos. Orientando a um pensamento de quantificar quão processual encontra-se a organização, quanto mais classificado à direita, maior o nível de processibilidade.

\subsection{PLANEJAMENTO ESTRATÉGICO}

É a partir da análise do seu ambiente que a organização conseguirá identificar a posição mais favorável para a escolha da uma estratégia que, de maneira coerente, adapte os elementos internos à sua disposição. Cada um dando suporte e complementando o outro, será esta sinergia que tornará possível a execução das estratégias. Por vez, o enfoque privilegiado nos processos permite a criação de uma teoria estratégica mais flexível (VASCONCELOS e CYRINO, 2000).

Já o planejamento estratégico (PE) começa com uma visão do que se pretende galgar; assim, são estipuladas etapas e metas para atingir esse objetivo (CUMMINGS e DAELLENBACH, 2009). Para as organizações, isto significa antever os cenários possíveis, determinar os objetivos e como alcançá-los, estudar melhorias e, assim, posicionar-se de forma mais competitiva no mercado (HARRISON, 1995). Também define formas de organizar sistematicamente a política e os esforços que levarão a organização para sua visão de futuro, analisando constantemente seus resultados através de uma realimentação organizada, determinando, assim, planos de contingência para antecipar possíveis mudanças à organização (STONEHOUSE e PEMBERTON, 2002; LISINSKI e SARUCKIJ, 2006). A essência do PE formal é a identificação sistemática de oportunidades e ameaças futuras que, combinadas com outras informações relevantes, fornecem bases para as melhores decisões, explorando as oportunidades e evitando as ameaças.

Em vista disso, o PE pode ser considerado de vital importância e responsável por promover a longevidade organizacional, sendo uma forma de exercício crítico para qualquer organização, de um ponto de origem para um ponto de destino, embasando-se principalmente

Revista Eletrônica de Estratégia \& Negócios, Florianópolis, v.7, n.2, mai./ago. 2014. 
ÍNDICE DE PROCESSIBILIDADE PARA TOMADA DE DECISÃO COMO APOIO AO PLANEJAMENTO ESTRATÉGICO Rafael Alvise Alberti - Elpidio Oscar Benitez Nara - João Carlos Furtado - Liane Mahlmann Kipper - Julio Cezar Mairesse Siluk

199

em como o negócio deve parecer de forma competitiva no futuro, com a duração exata dos planos estratégicos. Logo, a missão empresarial é determinar o que analisar e, após a análise, formular os objetivos. Deste modo, o uso de indicadores pode auxiliar na predição do tempo e modo necessários para o cobrimento das metas organizacionais (BREENE et al, 2007; FUENTESABATE et al, 2007).

\section{MATERIAIS E MÉTODOS}

Através de uma abordagem bibliográfico-exploratória, procurou-se embasar a pesquisa através da realização de um estudo bibliométrico para conhecer e analisar as contribuições culturais-científicas do passado acerca do determinado assunto, abrangendo a bibliografia de acesso público, com a finalidade de posicionar o pesquisador em contato direto com estudos já realizados (SEVERINO, 2004).

No aspecto qualitativo, a pesquisa foi desenvolvida através de uma abordagem interpretativa e natural, juntamente com o estudo dos acontecimentos em seu cenário naturalista, procurando interpretar e compreender os fenômenos e quais os significados atribuídos a eles (DENZIN e LINCOLN, 2000; GIL, 2008).

Quanto aos procedimentos metodológicos, em um primeiro momento buscou-se, através da pesquisa bibliográfica em base de dados (Periódicos Capes, Scielo, Anais de eventos e livros) com buscas por termos como processos - gestão por processos processibilidade/processabilidade, balizar uma definição sobre a abordagem organizacional por processos (adoção), um significado de ser processual, ou seja, a contextualização de um valor de processos - processibilidade, e as características marcantes das organizações assim orientadas.

Na sequência, foi analisado o Índice de Processibilidade a partir de uma abordagem lógico-dedutiva que, segundo Marconi e Lakatos (2007), é um método capaz de submeter uma ideia nova, formulada conjecturalmente e que ainda não foi justificada de algum modo (antecipação, hipótese, sistema teórico ou algo análoga), a partir da qual se pode tirar conclusões. Deste modo, parte-se de uma premissa maior, na qual a processibilidade é Revista Eletrônica de Estratégia \& Negócios, Florianópolis, v.7, n.2, mai./ago. 2014. 
intrínseca às características das organizações orientadas por processos, para uma menor, que seria a contemplação de todas estas características pelo índice, e enfim para a conclusão de que, se o índice contempla todas as características, logo consegue mensurar a processibilidade desejada.

Portanto, em linhas gerais, foi utilizada pesquisa bibliográfico-exploratória para contextualização dos principais tópicos (abordagem por processos, características das organizações por processos e contextualização do ser processual), criando um referencial teórico. Na sequência, a partir de uma abordagem lógico-dedutiva, avaliou-se o Índice de Processibilidade e buscou-se melhor entendimento de como seria a formulação de um novo indicador de processibilidade de gestão por processos nas organizações, através da análise dos resultados e a discussão do cenário encontrado.

\section{RESULTADOS E DISCUSSÕES}

\subsection{A ABORDAGEM POR PROCESSOS}

Com raízes no controle total da qualidade, a abordagem em processos ganhou notoriedade na década de 1990, como uma proposta conjunta de reengenharia e sistemas integrados de gestão (DAVENPORT, 1990). Neste período, o mercado apresentou um contexto de grandes transformações no interior das organizações, e o conceito que mais impactou sobre as organizações foi a GP, que buscava combinar a modelagem dos processos aliando a capacidade de mudança com a intensa participação das equipes envolvidas (JACOBS et al, 2009; ALBUQUERQUE, 2012; NARA et al, 2013).

Os processos relacionam-se com vários elementos, que permeiam toda a cultura organizacional e geram mudanças fundamentais na estrutura organizacional, onde agora a importância está nos processos, como um eixo de gestão e não sobre as funções desempenhadas por cada departamento. De acordo com o guia BPM CBOK (2009), a GP é uma abordagem disciplinada, que serve para identificar, projetar, implementar, avaliar e monitorar os processos de negócio, alcançando consistência e resultados de acordo com os objetivos Revista Eletrônica de Estratégia \& Negócios, Florianópolis, v.7, n.2, mai./ago. 2014. 
ÍNDICE DE PROCESSIBILIDADE PARA TOMADA DE DECISÃO COMO APOIO AO PLANEJAMENTO ESTRATÉGICO Rafael Alvise Alberti - Elpidio Oscar Benitez Nara - João Carlos Furtado - Liane Mahlmann Kipper - Julio Cezar Mairesse Siluk

201

estratégicos estabelecido pela organização, incluindo formas de agregar valor, melhorias, inovações e processos de gestão.

Esta abordagem por processos persegue dois objetivos de difícil conciliação: a formalização dos processos em modelos, a fim de estruturar o trabalho e melhorar o controle; e dar flexibilidade à organização, mantendo sua capacidade de responder a situações novas e imprevistas. A partir disto, projetos de GP devem buscar equilíbrio entre estes objetivos, assegurando a manutenção da flexibilidade organizacional (ALBUQUERQUE, 2012).

Desta forma, alguns dos objetivos da GP são: aumentar o valor do produto ou serviço percebido pelo cliente; aumentar a competitividade; sintetizar as ações de acordo com a estratégia definida, a fim de adicionar valor para o usuário; aumentar a produtividade e simplificar/eliminar os processos que não geram valor para o cliente. Assim, voltar-se para o cliente não é apenas uma forma de vantagem sobre os concorrentes, mas também pode se tornar um fator determinante para a melhoria contínua da qualidade de produto e processo (NETTO, 2006; SETIJONO e DAHLGAARD, 2007).

Logo, a GP pode ser entendida como um enfoque organizacional, que objetiva transcender as divisões funcionais, buscando a melhoria das decisões estratégicas, operacionais e de desempenho nos processos, através de uma visão sistêmica das atividades, interfaces funcionais, estruturas e recursos para suprir as necessidades, entregando valor ao usuário (LAURINDO e ROTONDARO, 2006; NARA et al, 2012). Levando uma visão integrada do trabalho, mostrando a correlação/dependência do ciclo completo do processo, dos fornecedores aos clientes, no qual todos participam com objetivos comuns, em busca de resultados satisfatórios.

Para facilitar a compreensão dessa mudança e buscar o comprometimento da equipe, ferramentas devem ser usadas para entender a situação externa e interna, como as coisas estão formatadas e no que o processo pode se tornar no futuro, após a sua reformulação (PAIM et al., 2009). Nesta primeira etapa (adoção da GP), é essencial dispor da maior 
quantidade de dados e informações possíveis do processo atual, tornando sua compreensão ampla e uniforme para todos os envolvidos.

\subsection{SER PROCESSUAL?}

Em se tratando de gestão de organizações, o termo processo possui diversas definições, análogas e complementares. No trabalho científico de Maranhão e Macieira (2008) são listadas algumas, como demonstrado no Quadro 2, as quais foram acrescidas de outras fontes e definições.

Quadro 2 - Definições do termo processo

\begin{tabular}{|c|c|}
\hline Fonte Bibliográfica & Definição de processo \\
\hline Norma NBR ISO 9000:2000 & $\begin{array}{l}\text { Conjunto de atividades inter-relacionadas ou interativas que } \\
\text { transformam insumos (entradas) em produtos (saídas). }\end{array}$ \\
\hline $\begin{array}{l}\text { Integration Definition for Modeling of } \\
\text { Process - IDEF0 }\end{array}$ & $\begin{array}{l}\text { Conjunto de atividades, funções ou tarefas identificadas, que } \\
\text { ocorrem em um período de tempo e que produzem algum } \\
\text { resultado. }\end{array}$ \\
\hline $\begin{array}{c}\text { HAMMER, M. } \\
\text { (Reengenharia - Revolucionando a } \\
\text { empresa e a Agenda) }\end{array}$ & $\begin{array}{l}\text { Reunião de tarefas ou atividades isoladas; grupo organizado de } \\
\text { atividades relacionadas que, juntas, criam um resultado de valor } \\
\text { para o cliente. }\end{array}$ \\
\hline $\begin{array}{c}\text { RAMASWAMY, R. } \\
\text { (Design anda Management os Service } \\
\text { Processes) }\end{array}$ & $\begin{array}{l}\text { Sequências de atividades que são necessárias para realizar as } \\
\text { transações e prestar o serviço. }\end{array}$ \\
\hline $\begin{array}{c}\text { GALLOWAY, D. } \\
\text { (Mapping Works Processes) }\end{array}$ & $\begin{array}{c}\text { Sequência de passos, tarefas ou atividades que convertem } \\
\text { entradas de fornecedores em uma saída. Um processo de } \\
\text { trabalho adiciona valor às entradas, transformando-as ou } \\
\text { usando-as para produzir alguma coisa nova. }\end{array}$ \\
\hline $\begin{array}{l}\text { RUMMLER, G.A. e BRACHE, A.P. } \\
\text { (Melhores Desempenhos das } \\
\text { Empresas) }\end{array}$ & $\begin{array}{l}\text { Uma série de etapas criadas para produzir um serviço ou um } \\
\text { produto. }\end{array}$ \\
\hline $\begin{array}{l}\text { HARRINGTON, H. J. } \\
\text { (Aperfeiçoando Processos } \\
\text { Empresariais) }\end{array}$ & $\begin{array}{l}\text { Um grupo de tarefas interligadas logicamente, que utilizam os } \\
\text { recursos da Organização para gerar resultados definidos, de } \\
\text { forma a apoiar os seus objetivos. }\end{array}$ \\
\hline $\begin{array}{l}\text { HAMMER, M. e CHAMPY, J. } \\
\text { (Reengineering the corporation) }\end{array}$ & $\begin{array}{c}\text { Um conjunto de atividades que, juntas, produzem um resultado } \\
\text { de valor para o consumidor. }\end{array}$ \\
\hline
\end{tabular}

Revista Eletrônica de Estratégia \& Negócios, Florianópolis, v.7, n.2, mai./ago. 2014. 
DAVENPORT, T. H.

(Reengenharia de Processos: como inovar na empresa através da tecnologia da informação)

\section{CRUZ, T.}

(Sistemas, métodos \& processos: administrando organizações por meio de processos de negócio)

ANTUNES Jr, J. A.

(Os paradigmas da engenharia de produção)

NETTO, C.

(Definindo gestão por processos)
Uma ordenação específica das atividades de trabalho no tempo e no espaço, com um começo, um fim, input e outputs claramente identificados, enfim, uma estrutura para ação.

Fonte: Adaptado de MARANHÃO e MACIEIRA (2008).

É a entrada de insumos em um ambiente formado por procedimentos, normas e regras que, ao processarem os insumos, transformam-nos em resultados que serão enviados

Constitui-se em um fluxo de objeto no tempo e no espaço. Estes objetos podem ser: materiais, ideias, informações, etc.

O modo como uma organização realiza seu trabalho - a série de atividades que executa para atingir um dado objetivo para um dado cliente, seja interno ou externo.

Em análise ao Quadro 2, as definições de processo comtemplam tópicos como:

- Conhecimento das atividades;

- Relações de entrada, recursos, regras e saídas;

- Relacionamento (mapeamento) das atividades;

- Valor ao cliente (atendimento às necessidades).

Assim, ser processual está alinhado à ideia da organização se conhecer através das atividades-chave, das relações entre estas (do fornecedor ao cliente), dos papéis funcionais, dos padrões de atuação-medição, e do conhecimento sobre o que é valor para o cliente, objetivando satisfazer as necessidades/desejos destes.

Logo, ser processual é a base para um modelo de gestão eficiente frente à nova realidade da concorrência e das expectativas mutáveis dos clientes.

\subsection{CARACTERÍSTICAS DAS ORGANIZAÇÕES}

Em reconhecimento ao ambiente/mercado cada vez mais competitivo, a agilidade em responder aos anseios dos clientes e a visão da organização como um sistema interligado são características marcantes. Assim, a visão tradicional/vertical foi substituída pela visão Revista Eletrônica de Estratégia \& Negócios, Florianópolis, v.7, n.2, mai./ago. 2014. 
horizontal/sistêmica (Quadro 3), fortemente vinculada à cadeia de valor, capaz de conviver com as novas exigências impostas pelo próprio ambiente.

Quadro 3 - Características das organizações verticais e horizontais

\begin{tabular}{|c|c|c|c|}
\hline Atributos & $\begin{array}{c}\text { Organização } \\
\text { Vertical }\end{array}$ & $\begin{array}{l}\text { Organização } \\
\text { Horizontal }\end{array}$ & Fontes: \\
\hline Estrutura Organizacional & $\begin{array}{l}\text { Rígida, por } \\
\text { tarefa }\end{array}$ & $\begin{array}{l}\text { Flexível, } \\
\text { por processo }\end{array}$ & \multirow{5}{*}{$\begin{array}{c}\text { GONÇALVES, 1997, 2000a, 2000b, } 2001 \\
\text { HAMMER e STANTON, } 1999 \\
\text { HARRINGTON, } 1991 \\
\text { IDEN, } 2012 \\
\text { JACOBS et al, } 2009\end{array}$} \\
\hline $\begin{array}{c}\text { Força de } \\
\text { Trabalho/Pessoal }\end{array}$ & Especializada & $\begin{array}{c}\text { Múltiplos } \\
\text { conhecimentos }\end{array}$ & \\
\hline Foco & Na empresa & No cliente & \\
\hline Ênfase & $\begin{array}{l}\text { Conteúdo } \\
\text { (produto) }\end{array}$ & Processo & \\
\hline Departamentalização & Alta & Baixa & \\
\hline Liderança & Chefe & $\begin{array}{l}\text { Dono do } \\
\text { processo }\end{array}$ & $\begin{array}{c}\text { KANTER, } 1997 \\
\text { KEEN, } 1997\end{array}$ \\
\hline Otimização & Da produção & Da empresa & MARTINHO e ROTONDARO, 2009 \\
\hline Informação & Hierárquica & Sem filtro & $\begin{array}{l}\text { MENDES et al, } 2012 \\
\text { MINTZBERG, } 2003\end{array}$ \\
\hline Metas & $\begin{array}{c}\text { Áreas } \\
\text { funcionais }\end{array}$ & $\begin{array}{l}\text { Processo } \\
\text { funcional }\end{array}$ & $\begin{array}{c}\text { MOHRMAN, } 1995 \\
\text { MONTEIRO e SORDI, } 2008\end{array}$ \\
\hline $\begin{array}{l}\text { Tecnologia da } \\
\text { Informação }\end{array}$ & Departamental & $\begin{array}{l}\text { Amplamente } \\
\text { empregada }\end{array}$ & PAIM et al, 2009 \\
\hline Trabalho & Individual & Cooperativo & SALERNO, 1994 \\
\hline Agilidade/Flexibilidade & Baixa & Elevada & $\begin{array}{l}\text { SCHIAR e DOMINGUES, } 2002 \\
\text { SCHÜTZ et al, } 2011\end{array}$ \\
\hline Contexto & Estabilidade & Dinamismo & TACHIZAWA, 1997 \\
\hline
\end{tabular}

Revista Eletrônica de Estratégia \& Negócios, Florianópolis, v.7, n.2, mai./ago. 2014. 


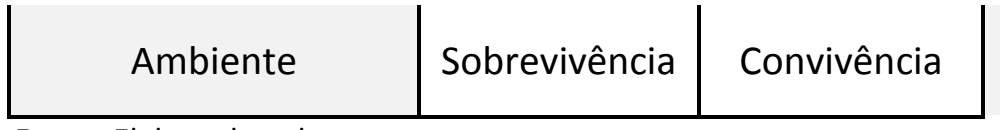

Fonte: Elaborada pelos autores.

A partir o Quadro 3, é possível visualizar a distinção das organizações verticais perante as horizontais, sendo que a estrutura reflete drasticamente na forma de gestão dos processos (MINTZBERG, 2003; PAIM et al., 2009). A seguir são explanadas, resumidamente, a partir das fontes citadas no quadro, cada uma destas características distintas.

\section{* Estrutura Organizacional}

Estrutura Vertical: Fundamentada na execução de tarefas, na qual a função de produção ocupa posição central, enquanto as outras são concebidas como de apoio; sustentada pelo paradigma do pensamento mecanicista-analítico, tais como hierarquia, disciplina, centralização da autoridade, divisão do trabalho, unidade de comando e outros.

Estrutura Horizontal: Atenção para os recursos e fluxos ao longo do processo de negócio; abordagem funcional pela lógica dos processos e unidades horizontais em paralelo; coordenação das atividades realizadas por diversas equipes de diversas áreas, dando menor ênfase à estrutura organizacional.

* Força de Trabalho

Estrutura Vertical: Predomina a especialização e o trabalho individual, com intensa busca por eficiência funcional; divisão exagerada de tarefas, contribuindo para o critério da otimização das áreas funcionais, levando à hiperespecialização da força de trabalho.

Estrutura Horizontal: Amplia os conhecimentos dos colaboradores, que começam a visualizar o processo do início ao fim, trabalhando em equipe/cooperação, ampliando os conhecimentos dos recursos humanos da organização.

Foco

Revista Eletrônica de Estratégia \& Negócios, Florianópolis, v.7, n.2, mai./ago. 2014. 
ÍNDICE DE PROCESSIBILIDADE PARA TOMADA DE DECISÃO COMO APOIO AO PLANEJAMENTO ESTRATÉGICO Rafael Alvise Alberti - Elpidio Oscar Benitez Nara - João Carlos Furtado - Liane Mahlmann Kipper - Julio Cezar Mairesse Siluk

Estrutura Vertical: Controle e o estudo de tempos e movimentos nas atividades de trabalho, foco na busca da maximização da eficiência no setor produtivo; organizações projetadas de maneira a privilegiar sua própria visão, sua realidade interna.

Estrutura Horizontal: Foco no cliente externo, já que os processos começam com o entendimento exato do que o cliente deseja, e termina com o mesmo adquirindo aquilo que atende as suas necessidades.

* Ênfase

Estrutura Vertical: Ao conteúdo que cada um realiza, não importando a atuação e nem o envolvimento dos demais; objetivos internos, com empregados e recursos em modo estático e produz um trabalho fragmentado.

Estrutura Horizontal: Equipes iniciam os trabalhos e asseguram que o mesmo seja realizado; ênfase na maneira como as atividades são realizadas, como as tarefas estão sendo transferidas, e a forma como as diferentes unidades podem contribuir em conjunto para resolver a tarefa.

* Departamentalização

Estrutura Vertical: Voltada às funções empresariais; impedâncias e perdas de carga devido aos muitos níveis hierárquicos; maior utilização de recursos devido aos esforços desprendidos em vencer as barreiras funcionais.

Estrutura Horizontal: Os processos atravessam as fronteiras das áreas funcionais, ultrapassam os setores provocando a existência de processos intrafuncionais e, por isso, há necessidade de uma visão sistêmica, que representa uma perspectiva diferente.

* Liderança

Revista Eletrônica de Estratégia \& Negócios, Florianópolis, v.7, n.2, mai./ago. 2014. 
Estrutura Vertical: O comando é centralizado; decisões tomadas pelos chefes/staffs; gestão baseada em comando e controle; processos são ignorados; funcionários têm foco restrito e o comando cabe unicamente aos gerentes.

Estrutura Horizontal: Os funcionários são organizados com base em um processo criador de valor, isto é, todas as ações dão suporte a este processo; surge o conceito de dono do processo, que é o responsável pelo mesmo desde o recebimento de matérias-primas até a distribuição do produto final, e tem influência sobre as mudanças; decisões são tomadas por grupos de trabalho no local organizacional em que são necessárias.

* Otimização

Estrutura Vertical: Otimização do processo produtivo (manufatura); durante décadas este processo foi o foco da redução de custos nas organizações.

Estrutura Horizontal: Aumenta a plasticidade organizacional, exige mudanças comportamentais radicais, diminui a burocracia e a departamentalização; aperfeiçoa as possibilidades da organização e reduz custos de coordenação e transação no funcionamento geral.

* Informação

Estrutura Vertical: Quebra das vias de comunicação entre departamentos com a criação de barreiras funcionais, que isolam áreas multidisciplinares atuantes nos mesmos processos; informação disputada entre setores como elemento de controle.

Estrutura Horizontal: O fluxo de informação é otimizado, sem bloqueios; informação não é elemento de controle e dominação, passando a ser elemento motivador de inovação, flexibilidade e integração.

* Metas

Estrutura Vertical: Metas para as áreas funcionais.

Revista Eletrônica de Estratégia \& Negócios, Florianópolis, v.7, n.2, mai./ago. 2014. 
ÍNDICE DE PROCESSIBILIDADE PARA TOMADA DE DECISÃO COMO APOIO AO PLANEJAMENTO ESTRATÉGICO Rafael Alvise Alberti - Elpidio Oscar Benitez Nara - João Carlos Furtado - Liane Mahlmann Kipper - Julio Cezar Mairesse Siluk

Estrutura Horizontal: Definidas para os processos essenciais, constituindo nível fundamental de avaliação do desempenho da organização.

* Tecnologia da Informação

Estrutura Vertical: Tratada de forma departamental, como a própria informação; influencia a forma de realizar os trabalhos daquela área.

Estrutura Horizontal: Nova abordagem e desenvolvimento de soluções em TI; a informação circula por todo o processo de negócio, e não mais apenas dentro dos departamentos.

* Trabalho

Estrutura Vertical: De forma individual e voltado às tarefas.

Estrutura Horizontal: Encoraja todos a sentirem-se responsáveis pelos processos, de maneira mais ampla; transparência nos processos e entendimento de sua interação.

* Agilidade e Flexibilidade

Estrutura Vertical: São comportamentos prejudicados devido à alta departamentalização, às barreiras funcionais, ao comando centralizado e à própria estrutura organizacional; assim, a dificuldade de lidar com as mudanças acaba por engessar a organização.

Estrutura Horizontal: Valoriza a agilidade e a flexibilidade, pois precisa estar constantemente vivenciando as mudanças, a fim de entregar ao cliente aquilo que atenda suas necessidades.

* Contexto

Estrutura Vertical: Pautada em um contexto de maior estabilidade, apresenta dificuldades de coexistir com um cenário mais dinâmico, de incertezas, de instabilidades, com Revista Eletrônica de Estratégia \& Negócios, Florianópolis, v.7, n.2, mai./ago. 2014. 
significativos obstáculos em longos prazos; operam em regime de estabilidade, com resultados satisfatórios em curto prazo e sensíveis dificuldades em longo prazo.

Estrutura Horizontal: Delineou as organizações em uma estrutura flexível, apta a atender a demanda de um ambiente mais complexo; as organizações tornam-se aptas às variabilidades do meio, convivendo com o dinamismo e a capacidade de mudanças.

* Ambiente

Estrutura Vertical: Sobrevivem ao ambiente devido ao engessamento às mudanças, à falta de cooperação/parcerias, e pela aceitação de que todos os recursos encontram-se dentro da própria organização.

Estrutura Horizontal: As parcerias e as redes de empresas reforçam que nem todos os recursos essenciais da empresa são internos; o ambiente mutável, dinâmico e descontínuo faz com que as organizações necessitem de uma grande adaptabilidade estratégica, como forma de conviver com o ambiente e obter sucesso.

A análise das características/atributos das organizações evidencia quão distintas são as estruturas verticais das horizontais, e como isso implica no comportamento da empresa, seja interno ou externo. Estas diferenças organizacionais evidenciam ainda mais a necessidade de um instrumento capaz de mensurar a situação de momento da empresa, frente às decisões de um planejamento estratégico perante a adoção da gestão de processos.

\subsection{PROCESSIBILIDADE EM GESTÃO}

A sinergia entre a escolha de uma abordagem por processos, o alinhamento às características das organizações horizontais, o conhecimento das atividades e suas relações, juntamente com a busca da satisfação do cliente através da entrega de um produto/serviço com o valor pretendido pelo mesmo, definem o que pode ser chamado processibilidade em gestão.

Revista Eletrônica de Estratégia \& Negócios, Florianópolis, v.7, n.2, mai./ago. 2014. 
A partir disto, avaliou-se o Índice de Processibilidade (Quadro 2)com enfoque voltado a legitimar a contemplação desta definição de processibilidade proposta, intrínseca às características das organizações horizontais.

Quadro 2 - Avaliação do Índice de Processibilidade frente às características organizacionais

\begin{tabular}{|c|c|c|}
\hline \multirow{2}{*}{$\begin{array}{l}\text { Fatores do Índice de Processibilidade } \\
\qquad \text { Gonçalves (2000b) }\end{array}$} & \multicolumn{2}{|c|}{$\begin{array}{l}\text { Características das organizações horizontais } \\
\qquad \text { (GP) }\end{array}$} \\
\hline & $\begin{array}{l}\text { Contempladas pelo } \\
\text { índice }\end{array}$ & $\begin{array}{l}\text { Não contempladas } \\
\text { pelo índice }\end{array}$ \\
\hline Importância do processo de manufatura em relação a & \multirow{10}{*}{$\begin{array}{c}\text { Estrutura Organizacional } \\
\text { Foco } \\
\text { Ênfase } \\
\text { Departamentalização } \\
\text { Trabalho } \\
\text { Agilidade e Flexibilidade } \\
\text { Contexto } \\
\text { Ambiente }\end{array}$} & \multirow{10}{*}{$\begin{array}{c}\text { Força de } \\
\text { Trabalho/Pessoal } \\
\text { Liderança } \\
\text { Otimização } \\
\text { Informação } \\
\text { Metas } \\
\text { Tecnologia da } \\
\text { Informação }\end{array}$} \\
\hline Quantidade de processos essenciais & & \\
\hline Tipo de estrutura/departamentalização & & \\
\hline Volume de trabalho em processos essenciais & & \\
\hline Interface com outras empresas por processos & & \\
\hline Importância de se voltar para o cliente externo & & \\
\hline Necessidade de flexibilidade & & \\
\hline Necessidade de agilidade & & \\
\hline Importância do Time to Market & & \\
\hline Tecnologia de produção & & \\
\hline
\end{tabular}

Fonte: Elaborada pelos autores.

Com o entendimento do quadro 2, observa-se que o indicador proposto por Gonçalves, no ano de 2000, já não é abrangente ao ponto de contemplar todas as principais características levantadas durante o estudo das publicações científicas atuais sobre organizações voltadas a GP. Segundo o método lógico-dedutivo, a premissa maior seria que a processibilidade está intimamente ligada a todas as características organizacionais horizontais, enquanto a premissa menor seria que o indicador deve contemplar todos estas características; logo, o indicador não seria capaz de medir com eficácia a grau de processibilidade pretendido.

Revista Eletrônica de Estratégia \& Negócios, Florianópolis, v.7, n.2, mai./ago. 2014. 
Cabe ressaltar que muitos dos fatores utilizados podem estar correlacionados e estarem presentes em mais de uma característica devido à abrangência dos referidos fatores, uma vez que a própria GP é a utilização conjunta de todos os elementos agregadores de valor ao cliente, dentro da organização.

Outras observações importantes são feitas, como a ausência de aspectos de planejamento estratégico, de a organização atuar com ações em acordo com seus objetivos; avaliação da competitividade da organização no mercado; e do ciclo de melhorias de processos, de conhecer o que agrega valor e os pontos de desperdício.

Por outro lado, cita-se a questão de voltar-se para o cliente externo no índice. Porém, na GP, o foco é o cliente, seja este interno ou externo; assim, poderia ser apenas modificado o fator, em busca de saber se a organização conhece seus clientes durante toda a cadeia produtiva. Também há o caso da quantidade em processos essenciais e o volume de trabalho nestes. Contudo, ressalva-se que não basta apenas conhece-los, quantificando e determinando o volume de trabalho, mas conhecer a relação entre processos, ou seja, o mapeamento do processo de negócio da organização.

Deste modo, partindo desta avaliação, procurou-se abranger os aspectos/fatores citados e elaborou-se uma proposta para o índice de processibilidade (Figura 2).

Figura 2 - Novo Índice de Processibilidade

Revista Eletrônica de Estratégia \& Negócios, Florianópolis, v.7, n.2, mai./ago. 2014. 


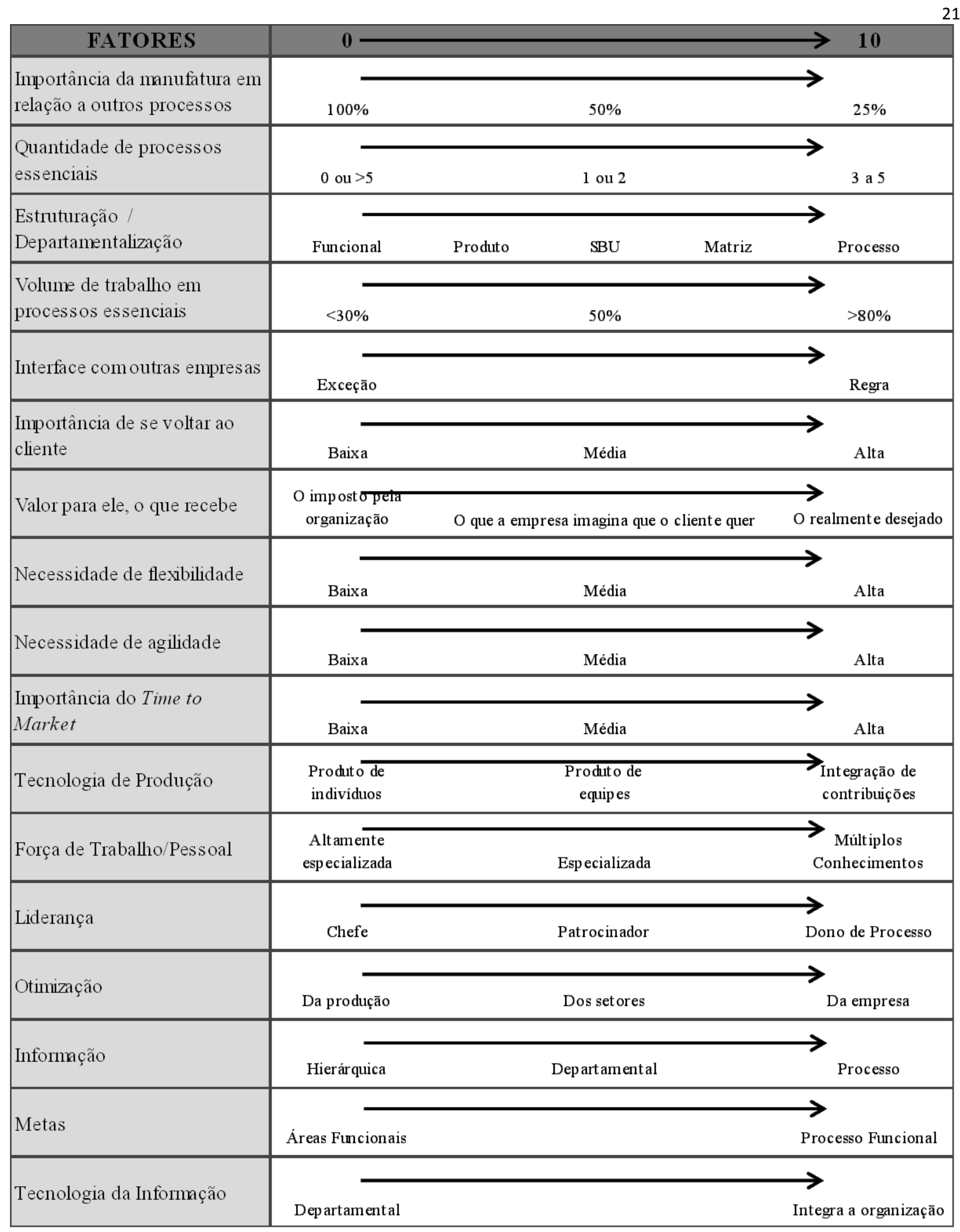


Fonte: Adaptado de Gonçalves (2000b).

Este novo modelo do Índice de Processibilidade ainda é considerado um instrumento indicativo e interpretado da mesma maneira que o original. Denota de uma abordagem simplificada através da avaliação de fatores importantes na GP das organizações, sendo que sua avaliação empírica resulta em maior ou menor recomendação por uma estrutura processual.

\section{CONSIDERAÇÕES FINAIS}

Certamente, devido ao ano no qual foi proposto o Índice de Processibilidade (2000), e com os estudos científicos mais recentemente publicados, este índice acrescido com os novos fatores pode ser utilizado como um balizador para apontar, inicialmente, um grau de processibilidade da organização, bem como o grau em que os processos são institucionalizados e efetivados. Assim, é possível definir as melhores ações para o planejamento estratégico, visando à implantação ou amadurecimento da visão organizacional voltada aos processos.

Foram também evidenciadas inúmeras características marcantes das organizações geridas por processos, características estas que afloram na forma de comportamentos organizacionais. Como referência para uma abordagem inicial da GP, temos metodologias de maturidade e planos de implantação amplamente defendidos e divulgados em textos científicos Revista Eletrônica de Estratégia \& Negócios, Florianópolis, v.7, n.2, mai./ago. 2014. 
e/ou acadêmicos. Porém, havia carência de um indicador robusto que avaliasse quão processual a organização se encontra, e que fosse capaz de fornecer informações de valia para orientar ações de um planejamento estratégico, concentrando, de maneira eficiente, a atenção e a energia da organização que pretender aderir à GP.

As organizações não devem iniciar esta mudança de forma pontual e sem embasamento sobre os aspectos organizacionais necessárias. É imprescindível ter noção das possibilidades iniciais e, assim, poder traçar metas realistas com compatibilidade entre o modelo de gestão e o modelo organizacional.

Já na proposta de avaliar o índice de processibilidade proposto por Gonçalves, foi obtido êxito. Através do estudo teórico, foram levantadas informações pertinentes que puderam servir como embasamento para a avaliação e, juntamente a isso, mesclar novos atributos e fomentar um novo indicador capaz de agregar uma informação de maior relevância com, enfoque ao planejamento estratégico organizacional.

Como limitação, a pesquisa trouxe à tona que um índice de processibilidade quantificável só se faz relevante frente a uma base de dados que consiga categorizar o valor encontrado com algum nível entre organizações ou entre setores de atuação, dessa forma podendo nortear, através da informação gerada, a melhor decisão gerencial atrelada ao planejamento estratégico já vigente. O próprio Gonçalves comenta que cada organização tem suas particularidades, o que faz com que a importância de alguns atributos assuma valores mais relevantes que outros. Esta limitação presente galga uma possibilidade de estudos futuros a fim de criar esse banco de dados e validar o instrumento vindouro como pré-indicador de processibilidade organizacional.

Portanto, os trabalhos de Gonçalves, frente à abordagem dos processos, foram/são destaque e, certamente, considerados entre as mais relevantes contribuições a respeito do assunto. O autor é pioneiro no processo da tentativa de quantificar a processibilidade e, assim, classificar as empresas em estágios de maturidade processual, de modo a ser possível avaliar a 
ÍNDICE DE PROCESSIBILIDADE PARA TOMADA DE DECISÃO COMO APOIO AO PLANEJAMENTO ESTRATÉGICO Rafael Alvise Alberti - Elpidio Oscar Benitez Nara - João Carlos Furtado - Liane Mahlmann Kipper - Julio Cezar Mairesse Siluk

215

situação da organização e situá-la a respeito das expectativas dos seus gestores. Desta forma, a contribuição de Gonçalves impactou fortemente na quebra de paradigmas organizacionais e na adoção de um norte voltado à satisfação dos clientes.

\section{AGRADECIMENTOS}

Agradecimentos o auxílio disponibilizado pela CAPES e pelo PPGSPI (UNISC).

\section{REFERÊNCIAS}

ABPMP. Association of Business Process Management Professionals, Guide to the Business Process Management Common Body of Knowledge (BPM CBOK ${ }^{\circledR}$ ), v. 2. 2009.

ALBUQUERQUE, J.P. Flexibilidade e modelagem de processos de negócio: uma relação multidimensional. RAE - Revista de Administração de Empresas. vol. 52, no.3, São Paulo, Mai./Jun. 2012.

AYRES, T. C. de S. Da escola tradicional á gestão por processos: uma perspectiva. In: IX SIMPÓSIO DE ENGENHARIA DE PRODUÇÃO - SIMPEP, São Paulo. Anais... 2002.

BATEN, K. Processability Theory and German Case Acquisition. Language Learning. Vol 61. N.2, pp. 455-505, 2011.

BITENCOURT, C. S.; PANDOLFELLI, V. C. Refratários contendo carbono: propriedades, características e variáveis em sua composição. Cerâmica. São Paulo, v. 59, n. 349, Mar. 2013.

BORGES, J. Desenvolvimento de um modelo neurofuzzy de rede neural artificial para aplicação em processamento de materiais poliméricos. IJIE - Iberoamerican Journal of Industrial Engineering, v. 3, n. 1, p. 62-79, Jul. 2011.

BRASIL. Constituição (1988). Constituição da República Federativa do Brasil. Brasília, DF: Senado Federal, 1988.

BREENE, R.T.; NUNES, P.F.; SHILL, W.E. The chief strategy officer. Harvard Business Review, v. 85, n. 10, p. 84-93, 2007.

BRITO, R.P.; BRITO, L. A. L. Vantagem Competitiva, Criação de valor e seus efeitos sobre o Desempenho. RAE - Revista de Administração de Empresas, v. 52, n.1, São Paulo, Jan./Fev. 2012.

Revista Eletrônica de Estratégia \& Negócios, Florianópolis, v.7, n.2, mai./ago. 2014. 
ÍNDICE DE PROCESSIBILIDADE PARA TOMADA DE DECISÃO COMO APOIO AO PLANEJAMENTO ESTRATÉGICO Rafael Alvise Alberti - Elpidio Oscar Benitez Nara - João Carlos Furtado - Liane Mahlmann Kipper - Julio Cezar Mairesse Siluk

CARPENTER, S. K.; WILFORD, M. M.; KORNELL, N.; MULLANEY, K. M. Appearances can be deceiving: instructor fluency increases perceptions of learning without increasing actual learning. Psychonomic Bulletin \& Review, v. 20, n. 6, p. 1350-1356, dez. 2013.

CATEN, C. S.; FRANZ, L. A. dos S. Aplicação e Análise do Seis Sigma em uma Indústria do Ramo Petroquímico. In: II Semana de Produção e Transportes. Porto Alegre, Brasil. Anais... Brasil, 2002.

CHERMAN, A.; ROCHA-PINTO, S. R. Valoração do conhecimento: significação e identidade na ação organizacional. RAE - Revista de Administração de Empresa, v.53, n.2, São Paulo Mar./Abr. 2013.

COX, R.F.; ISSA, R.R.A.; AHERNS, D.. Management's perception of key performance indicators for construction. Journal of Construction Engineering and Management , v. 129, n. 2,p. 142 - 151, 2003.

CUMMINGS, S.; DAELLENBACH, U. A guide to the future of strategy: the history of long range planning. Long Range Planning. v. 42, n. 2, p. 234-63, 2009.

DAVENPORT, T. H. The new industrial engineering: information technology and business process redesign. Sloan Management Review, v. 31, n. 4, p. 11-27, 1990.

DAVENPORT, T. Reengenharia de processos. Rio de Janeiro: Campus, 1994.

DENZIN, N. K.; LINCOLN, Y. S. O Planejamento da Pesquisa Qualitativa: teorias e abordagens. 2. ed. Porto Alegre: Bookman, 2000.

FREDERICO, G. F.; TOLEDO, J. C. A Gestão por Processos: um estudo de caso de um operador logístico. IN: XXVIII ENCONTRO NACIONAL DE ENGENHARIA DE PRODUÇÃO -ENEGEP, Rio de Janeiro, Anais... 2008.

FUENTE-SABATE', J.M.; de la RODRIGUEZ-PUERTA, J.; VICENTE-LORENTE, J.; ZUNIGA-VICENTE, J.A. Do stable strategic time periods exist? Towards new methodological and theoretical insights. Managerial \& Decision Economics, v. 28, n. 3, p. 171-80, 2007.

GIL, A. C. Como elaborar projetos de pesquisa. 5. Ed. São Paulo: Atlas, 2008.

GONÇALVES, J. E. L. Os novos desafios da empresa do futuro. RAE - Revista de Administração de Empresas, v. 37, n. 3, p. 10-19, Jul./Set. 1997.

GONÇALVES, J. E. L. As empresas são grandes coleções de processo. RAE . Revista de Administração de Empresas, v. 40, n. 1, p. 6-19, Jan./Mar. 2000a.

GONÇALVES, J. E. L. Processo, que processo? RAE - Revista de Administração de Empresas, v. 40, n. 4, p. 6-19, Out/Dez. 2000b.

Revista Eletrônica de Estratégia \& Negócios, Florianópolis, v.7, n.2, mai./ago. 2014. 
ÍNDICE DE PROCESSIBILIDADE PARA TOMADA DE DECISÃO COMO APOIO AO PLANEJAMENTO ESTRATÉGICO Rafael Alvise Alberti - Elpidio Oscar Benitez Nara - João Carlos Furtado - Liane Mahlmann Kipper - Julio Cezar Mairesse Siluk

GONÇALVES, J. E. L. Gestão por Processos: uma visão prática. In: WOOD JR, T. (Cood.). Gestão Empresarial: oito propostas para o terceiro milênio. São Paulo: Atlas, 2001.

HAMMER, M.; STANTON, S. How process enterprises really work. Harvard Business Review, v. 77, n. 6, p. 108-118, Nov./Dec. 1999.

HARRINGTON, J. Business process improvement. New York: McGraw Hill, 1991.

HARRISON, E. F. Strategic planning maturities: Shows the dynamic interrelationship between planning horizons and strategic planning maturities. Management Decision, v. 33, n. 2, p. 48 55, 1995.

IDEN, J. Investigating process management in firms with quality systems: a multi-case study. Business Process Management Journal, v. 18 n. 1, p. 104-121, 2012.

JACOBS, G; KIPPER, L. M.; ELLWANGER, M.C.; FROZZA, R.; NARA, E. O. B. Por onde começar a gestão por processos? Uma análise sobre metodologias. In: XVI SIMPÓSIO DE ENGENHARIA DE PRODUÇÃO - SIMPEP, São Paulo. Anais... 2009.

KANTER, R. M. Frontiers of management. Cambridge: Harvard Business School Press, 1997.

KAUFMANN, L.; BECKER, A. Overcoming the Barriers During Implementation and Use of the Balanced Scorecard by Multinational Companies in Brazil. Latin American Business Review, v. 6, n. 3, p. 39-61, 2005.

KEEN, P. G. The process edge. Cambridge: Harvard Business School Press, 1997.

KIPPER, L. M.; ELLWANGER, M. C.; JACOBS, G.; NARA, E. O. B.; FROZZA, R. Gestão por processos: comparação e análise entre metodologias para implantação da gestão orientada a processos e seus principais conceitos. TECNO-LÓGICA, v. 15, n. 2, p. 89-99, jul./dez. 2011.

LAURINDO J. B.; ROTONDARO, G. Gestão integrada de processos e da Tecnologia da Informação. São Paulo: Atlas, 2006.

LISINSKI, M.; SARUCKIJ, M. Principles of the Application of Strategic Planning Methods. Journal of Business Economics and Management, v. VII, n. 2, p. 37-43, 2006.

MARANHÃO, M.; MACIEIRA, M.E. O processo nosso da cada dia: modelagem de processos de trabalho. 1. Ed. Rio de Janeiro. Qualitymark Editora, 2008.

MARCINIUK, R. M. B. A teoria da processabilidade e a aquisição de L2. ANALECTA. Guarapuava, Paraná, v.8, n. 2, p.11-27, jul./dez. 2007.

MARCONI, M. de A.; LAKATOS, E. M. Fundamentos de metodologia científica. 6. ed. São Paulo: Atlas, 2007.

Revista Eletrônica de Estratégia \& Negócios, Florianópolis, v.7, n.2, mai./ago. 2014. 
ÍNDICE DE PROCESSIBILIDADE PARA TOMADA DE DECISÃO COMO APOIO AO PLANEJAMENTO ESTRATÉGICO Rafael Alvise Alberti - Elpidio Oscar Benitez Nara - João Carlos Furtado - Liane Mahlmann Kipper - Julio Cezar Mairesse Siluk

MARTINHO, G.B.; ROTONDARO, R. G. Aplicação da gestão por processos em empresa do setor de varejo de supermercados: estudo de caso. In: XXIX ENCONTRO NACIONAL DE ENGENHARIA DE PRODUÇÃO - ENEGEP, Salvador. Anais... 2009.

MELLO, Ivana L.; et al . Influência das características estruturais sobre a processabilidade do polibutadieno alto cis. Polímeros. São Carlos, v. 14, n. 4, 2004.

MENDES, F. I.; KIPPER, L. M.; NARA, E. O. B. Gestão por processos: uma metodologia para gerenciamento de projetos na indústria. In: VIII CONGRESSO NACIONAL DE EXCELÊNCIA EM GESTÃo, Rio de Janeiro. Anais... 2012.

MELNYK, S.A., STEWART, D.M. and SWINK, M. Metrics and performance measurement in operations management: dealing with the metrics maze. Journal of Operations Management, $v$. 22, p. 209-217, 2004.

MINTZBERG, H. Criando Organizações Eficazes: Estruturas em Cinco Configurações. 2 ed. São Paulo: Atlas, 2003.

MOHRMAN, S.; et al. Designing team-based organizations. San Francisco: Jossey-Bass, 1995.

MONTEIRO, J. M.; SORDI, J. O. de. Gestão por processos de negócios uma ferramenta de orquestração da cadeia logística. In: XV SIMPÓSIO DE ENGENHARIA DE PRODUÇÃO - SIMPEP. São Paulo. Anais... 2008

MÜLLER, C. J. A managerial model that integrates Strategic Planning, Business-Process Management and Performance Evaluation (MEIO - Modelo de Estratégia, Indicadores e Operações). Tese (Doutorado em Engenharia) - Universidade Federal do Rio Grande do Sul, Porto Alegre, 2003.

NARA, E.O.B; CLANE, S.R. Mapa estratégico, uma representação gráfica do balanced scorecard, ferramenta para otimização da tomada de decisões: Estudo de caso de uma indústria de porte médio", In. XII SIMPÓSIO DE ENGENHARIA DE PRODUÇÃO - SIMPEP. Bauru. Anais... 2005.

NARA, E. O. B.; KIPPER, L. M.; LIMA, C. C. B.; STORCH, L. A. A visão da gestão por processos em seus diferentes níveis - estudo de caso de maturidade de processos. In: VIII CONGRESSO NACIONAL DE EXCELÊNCIA EM GESTÃO, Rio de Janeiro. Anais... 2012.

NARA, E .O. B.; KIPPER, L. M.; BENITEZ, L. B.; FORGIARINI, G.; MAZZINI, E. Strategies used by a meatpacking company for market competition. Business Strategy Series, v. 14, n. 2/3, p.72 79, 2013.

NETTO, C. A. A. Definindo gestão por processos: características, vantagens, desvantagens, in: LAURINDO, F. e ROTONDARO, R. (Eds), Gestão integrada de processos e da tecnologia de Informação. São Paulo, Atlas, p. 14-37. 2006.

Revista Eletrônica de Estratégia \& Negócios, Florianópolis, v.7, n.2, mai./ago. 2014. 
ÍNDICE DE PROCESSIBILIDADE PARA TOMADA DE DECISÃO COMO APOIO AO PLANEJAMENTO ESTRATÉGICO Rafael Alvise Alberti - Elpidio Oscar Benitez Nara - João Carlos Furtado - Liane Mahlmann Kipper - Julio Cezar Mairesse Siluk

PAIM, R.; CARDOSO, V.; CAULLIRAUX, H.; CLEMENTE, R. Gestão de Processo: pensar, agir e aprender. Porto Alegre: Bookman, 2009.

ROGRIGUES, J. da S. FUJIYAMA, Roberto Tetsuo. OLIVEIRA, Dênio Raman Carvalho. Análise fractográfica de compósitos de matriz poliéster e resíduos da indústria madeireira. In. VI Congresso Nacional de Engenharia Mecânica. Paraíba, Brasil. Anais... Brasil 2010.

RUMMLER, G.; BRACHE, A.; Improving performance. San Francisco: Jossey-Bass, 1997.

SALERNO, M. S. Mudança Organizacional e trabalho direto em função de flexibilidade e performance da produção industrial. Produção, v. 4, n. 1, p. 5-22, 1994.

SCHIAR, L.; DOMINGUES, J. Organizações voltadas para processos: um paralelo com as organizações funcionais. In: XXII ENCONTRO NACIONAL DE ENGENHARIA DE PRODUÇÃO ENEGEP. Curitiba. Anais... 2002.

SCHÜTZ, A. B. B.; DORFEY, D. E.; KIPPER, L. M.; NARA, E. O. B. Gestão por processos e estruturas organizacionais: um estudo teórico sobre artigos publicados em eventos científicos. In: XVIII SIMPÓSIO DE ENGENHARIA DE PRODUÇÃO - SIMPEP. São Paulo. Anais... 2011.

SETIJONO, D; DAHLGAARD, J.J. Customer value as a key performance indicator (KPI) and a key improvement indicator (KII). Measuring Business Excellence, v. 11, n. 2, p. 44-61, 2007.

SEVERINO, A. J. Metodologia do Trabalho Científico, São Paulo, Cortez, 2004.

STONEHOUSE, G.; PEMBERTON, J. Strategic planning in SMEs-some empirical findings.

Management Decision, v. 40, n. 9, p. 853-61, 2002.

STORCH, L.A; NARA, E.O.B; KIPPER,L.M. The use of process management based on a systemic approach. International Journal of Productivity and Performance Management, v. 62, n. 7, 2013.

TACHIZAWA, T. Organização Flexível: qualidade na gestão por processos. São Paulo: Atlas, 1997.

TOOR, S.R., OGUNLANA, S.O. Beyond the 'iron triangle': Stakeholder perception of key performance indicators (KPIs) for large-scale public sector development projects. International Journal of Project Management, v.28, p. 228-236, 2010.

VASCONCELOS, F. C.; CYRINO, Á. B. Vantagem Competitiva: os Modelos Teóricos Atuais e a Convergência Entre Estratégia e Teoria Organizacional. RAE-Revista de Administração de Empresas, v. 40, n. 4, São Paulo, Out./Dez. 2000.

YU, I.; KIM, K.; JUNG, Y.; CHIN, S. Comparable Performance Measurement System for Construction Companies. Journal of Management in Engineering, v. 23, n. 3, p. 131- 139, 2007.

Revista Eletrônica de Estratégia \& Negócios, Florianópolis, v.7, n.2, mai./ago. 2014. 
ZITEK, E. M.; TIEDENS, L. Z. The Fluency of Social Hierarchy: The Ease With Which Hierarchical Relationships Are Seen, Remembered, Learned, and Liked. Journal of Personality and Social Psychology, v. 102, n. 1, p. $98-115,2012$. 